\title{
Understanding body image perception and body image discontentment in early adolescence
}

\section{Radhika P Hedaoo ${ }^{1,}$ SubbaRao M Gavaravarapu ${ }^{2}$}

${ }^{1}$ Assistant Professor, Nutrition and Dietetics Program, Symbiosis Institute of Health Sciences, Symbiosis International (Deemed University), Lavale, Pune; ${ }^{2}$ Scientist "E", Extension and Training Division, ICMR-National Institute of Nutrition, Department of Health Research, Ministry of Health \& Family Welfare, Govt. of India, Jamai-Osmania Hyderabad

\begin{tabular}{|c|c|c|c|c|c|c|c|}
\hline Abstract & Introduction & Methodology & Results & Conclusion & $\underline{\text { References }}$ & Citation & oles / Figures \\
\hline \multicolumn{8}{|c|}{ ing Author } \\
\hline \multicolumn{7}{|c|}{$\begin{array}{l}\text { Dr. Subba Rao M Gavaravarapu, Extension and Training Division, Group Leader, Media, Communication } 8 \\
\text { Extension, ICMR-National Institute of Nutrition, Jamai-Osmania PO, Hyderabad - 500007, INDIA } \\
\text { E Mail ID: subbarao.gm@icmr.gov.in }\end{array}$} & 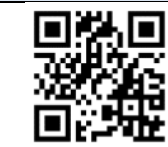 \\
\hline
\end{tabular}

\section{Citation}

Hedaoo RP, Gavaravarapu SR. Understanding body image perception and body image discontentment in early adolescence. Indian J Comm Health. 2020;32(2):411-417.

Source of Funding: Indian Council of Medical Research (ICMR) - Indian Council of Social Science Research (ICSSR) Joint funding Conflict of Interest: None declared

\section{Article Cycle}

Received: 28/05/2020; Revision: 11/06/2020; Accepted: 23/06/2020; Published: 30/06/2020

This work is licensed under a Creative Commons Attribution 4.0 International License.

\section{Abstract}

Background: The mounting trends of beauty perceptions have contributed to distorted body image among adolescents. This demand understanding about current pointers of body image satisfaction to prevent eating disorders associated with mismanagement of weight in adolescents. Aim \& Objective: The objectives of this cross-sectional study were to apprehend body image perception and dissatisfaction among adolescents (12-14years) across the genders and associate it with their actual BMI along with identifying the factors influencing body image perception. Settings and Design: A structured questionnaire was developed and administered on randomly selected 112 adolescents (68\% boys \& 34\% girls, $12-14$ years), mean age $=12.8 \pm 0.45$ from urban coeducational school of western India. Anthropometric measurements were taken with standardized tools and BMI z-scores were calculated. The actual and perceived weight was compared using paired t-test and descriptive statistics. Association between body image indicators, gender, and BMI were assessed using Chi-square test and One-way ANOVA. Factor analysis was done by Principal component analysis. Results: There was a significant difference in the perceived $(M=2.31, S D=0.93)$ and actual $B M I(M=1.96, S D=0.69), p=0.002$. A significant association between gender and the influence of media idols, discrimination due to physical appearance and BMI was observed ( $p \leq .0 .005)$. Self-perception and judgements of others, behaviors related with self-fixation, social influence and inappropriate dietary practices and comparison with models and actors were the emerging factors identified. Conclusion: The body image perception was distorted among adolescents of both sexes, with higher body image discontent shown by girls. The perceived body image, when compared with their BMI was found to be incongruent across sexes.

\section{Keywords}

\section{Body Image; Body Perception; Adolescents}

\section{Introduction}

Early adolescence has been recognized as a transitional risk period for developing faulty body image as adolescents experience various physical, psychological and emotional instabilities such as the search for identity, social acceptance, and peer pressures. $(1,2)$ The growing evidence of depression, psychopathology and low selfesteem among adolescents often points at body image discontent and weight dissatisfaction as a significant contributing factor. $(3,4)$
The concept of body image dynamically evolves through ideas, feelings, and senses unconsciously throughout life. (5) The obsession with body shape and size developed during adolescence in due course contours their body image perception(.6) Also, the image projected by action figures, dolls, film personalities is a contributor to the development of perceptions related to body image from an early age .However, they are in no way representative of the average Indian physiques across the genders. Body dissatisfaction is a growing public health concern as it is one of the major reasons for eating disorders and fad diets 

among adolescents.(7)The unrealistic image created and propagated by the mass media are also often blamed for faulty diet trends followed by adolescence.(8) The extensive use of highly visual social media (HVSM) for example, Instagram and Snap chat focusing on celebrities and peers have specified rising body image apprehensions among adolescents.(9) The perpetual skirmish vouching ultra-thin models in the mass media is a substantial contributor to negative body image among individuals and adolescents are no exception to this.(10)

Often the perceptions thus developed may not match with their actual body weight or nutritional status. If these perceptions are gauged, suitable policy and communication strategies can be planned. Given this background, this study was undertaken to comprehend the judgment of adolescents about their body shape, size and the prevalence of dissatisfaction towards their bodies in relation to their actual nutritional status.

\section{Aims \& Objectives}

\section{Primary objectives:}

- To assess the body image perception and body image discontent among adolescents

- To compare body image perception and discontent with their BMI levels.

\section{Secondary objective:}

- To identify the factors leading to body image perceptions and assess their variance among adolescents.

\section{Material \& Methods}

Study design and participants: This was cross-sectional study conducted on randomly selected 112 adolescents ( $n=74$ boys and 38 girls) between the age group of 12-14 years recruited from an urban middle income coeducation school of Pune city, in western India.

Ethics: Approvals from the Independent Ethics Committee (IEC) of Symbiosis International (Deemed University) and school management were taken. Written informed consents of the parents, and assent of adolescents were taken. The adolescents were oriented about the questionnaire to be administered in advance and were informed about their right to withdraw from the study anytime.

Inclusion and exclusion criteria: Apparently healthy adolescents with no known psychotic illnesses or eating disorders were included in the study. Participants with known mental health issues and physical disabilities were excluded.

Questionnaire development and administration: A structured short questionnaire containing dichotomous and polychotomous responses for various indicators of body image perception was developed and adapted from validated body image questionnaires developed and widely in use in UK and Spain. $(11,12)$ Questions having dichotomous responses were scored as 0 and 1 and questions having polychotomous responses were scored on a scale of 0 to 2 .

The content of the questionnaire was assessed by a panel of pediatrician, a psychologist, and a nutritionist. A pool of thirty questions was generated and panel rated the questions as most relevant, relevant and least relevant. The final questionnaire consisted of fourteen questions on various indicators of body image perception such as body size perception, satisfaction with their looks and body, choices to change physical appearance, influence of peers, social media, celebrities and idols, discrimination due to body image, following of diet, opinions of others, comparisons with models, actors and others, frequency of beauty apps, mirror usage and selfies to check physical appearance. The questionnaire was pretested on adolescent boys and girls $(n=10)$ and with minor modification, it was administered through interview mode Every answer entered in the questionnaire was read out for confirmation to avoid any recording errors.

The socio-demographic profile of adolescents was assessed using Kuppuswamy socioeconomic scale, 2018.(13) Questions related to their ethnicity, type of family, age and gender were also included in the questionnaire.

Anthropometric measurements: In order to assess the actual nutritional status of the participants, their body weights were measured in light clothing using a TANITA digital weighing scale Model 240MA (TANITA Corporation, Japan) to the nearest $0.1 \mathrm{~kg}$ by adjusting the average clothes weight of 0.5 kilograms. A portable SECA Stadiometer (Model 213 - SECA, Germany) was used to measure the height to the nearest $0.1 \mathrm{~cm}$. BMI z-scores for age and sex were calculated using WHO Anthroplus software version 1.03 and classified as underweight (BMI below 3rd percentile), normal weight (between 3rd and 85th percentile), overweight (between 85 and 97th percentile) and obese (above 97th percentile)(14). The anthropometric measurements were collected after a week of administration of the questionnaire to avoid bias in responses while answering the questionnaire.

Data analysis: The data was entered and analyzed using IBM SPSS Version 20 for Windows (Armonk, NY: IBM Corp). Descriptive statistics were calculated for sociodemographic data, mean age, anthropometric measurements and association between body image indicators, gender and BMI were assessed using the Chisquare test. One-way ANOVA was performed to observe the difference between groups of BMI categories and indicator items of the questionnaire on body image perception. Paired t test was used to compare the actual $\mathrm{BMI}$ with the perceived BMI. Association between body image indicators, gender, and BMI were assessed using Chi-squared test and One-way ANOVA. Factor analysis was performed by principal component analysis on 14 items of the questionnaire to extract the variables component-wise and assess the variance among them to 
understand the important factors that influence the body image perceptions and discontent.(15)

\section{Results}

The mean (+SD) age of adolescents was $12.8 \pm 0.45$. The adolescents belonged to upper middle income group. The socio-demographic profile of adolescents along with the anthropometric data is represented in (Table-1). As per the BMI z-score classification, 54\% were underweight and almost a quarter of them were overweight or obese (Figure 1). The responses to indicators of body image perceptions gender-wise are represented in (Table-2). The paired t-test analysis revealed a significant $(p=0.002)$ difference in the perceived and actual BMI.

ANOVA revealed that there was a significant $(p=0.045)$ effect of BMI with discrimination and mistreatment observed among adolescents. Also, a significant $(p=$ 0.047) effect of BMI with the diets being followed presently or in past was observed. Chi-squared test revealed significant associations between body image perception indicators, BMI and gender as represented in (Table-3).

A principal component analysis (PCA) was performed on the 14 item questionnaire which suggested four most important components which explained a total variance of $58.75 \%$, as represented in (Table-4). The first component represented largely the body image self-perception related items and judgements by others. The maximum proportion of variance $20.98 \%$ on items such as contention related with body and physical appearance, choices to change appearance, perception of body size and weight, opinions of friends, family, and others, discrimination and mistreatment observed because of physical appearance. The second component showed a variance of $18.7 \%$ showing behaviors related with selffixation such as the use of the mirror, beauty apps, clicking selfies and comparison with others. The third component grouped variables such as choices of idols, choices presented in the change of appearance and physical appearance suggestive of happiness suggesting of social influence as a component, while the fourth component grouped the practices such as comparison with others and dieting practiced by adolescents suggesting inappropriate dietary practices and undue comparison as a component . The components showed a variance of about 9.7 \%and 9.2 $\%$ respectively.

\section{Discussion}

This cross-sectional study offered an insight into the various dimensions of body image perception and dissatisfaction among the adolescents' boys and girls. There were no significant associations between the sociodemographic profile and indicators of body image perception in this study which suggests that body shape discontent is prevalent across the socio, economic and gender groups. The anthropometric measurements of adolescents suggested prevalence of dual malnutrition across genders in terms of under nutrition as well as over nutrition. However, the body weight and size perception were distorted and did not align with the reality. It was observed that $20.2 \%$ of boys were overweight. However, $42 \%$ perceived themselves to be overweight. Likewise, $42 \%$ of girls perceived them to be overweight but only $23.6 \%$ were actually overweight. It was observed that $44.7 \%$ of girls were underweight however unexpectedly none of the girls perceived themselves to be underweight or too thin. Also, only $2 \%$ of the boys perceived themselves to be underweight or too thin but as per BMI $z$-scores, $58.1 \%$ of boys were underweight. These findings are in tune with earlier studies conducted in the Indian context. Similar Indian studies have shown a misperception of body image as compared to their body mass index and weight status. (16)

There was a significant difference observed between dissatisfaction related to looks and appearance among the girls and boys. The study revealed that girls were more dissatisfied compared to boys about the way they looked and also the majority of girls wanted to change their body shape. Though both the sexes idolized actors and models, girls articulated to idolize models and actors significantly more than boys. It has been evidenced that media figures are considered as 'pseudo friends' by adolescents and they form a para-social connection with media figures rapidly. (17) This is indicative of the high influence of media figures upon adolescents. Frustrations and insufficiency among girls was significantly higher compared to boys when they compared with models and actors. The contributing factor is the stereotypical portrayal of girls and women in media which contributes to unrealistic body image especially a thin body image. The world of animation and multimedia is also no exception as it portrays women and girls having thinner waistlines and unrealistic body frames compared to the other gender. $(18,19)$ Such frustrations observed among adolescent girls are suggestive of physiological changes taking place as the girls are undergoing pubertal changes and are moving away from thin-ideal body types.(20) Girls were also leading in the use of beauty apps to correct body shape and appearance of their images and photographs. These results are in line with a study in which adolescent girls showing social comparison tendencies were using manipulated and enhanced images on social media. (21)

Both girls and boys often compared themselves with the peers and people around them who they thought had better figure or physique respectively. However, girls compared themselves more with people around them having better figures. There was a significant difference between the BMI categories of adolescents and discrimination, mistreatment observed among adolescents. It was observed that overweight and underweight adolescents showed higher discrimination and mistreatment compared to normal-weight 
adolescents. Similarly, observance of dieting in past or dieting being followed presently without supervision from a nutritionist/dietician/doctor was observed among overweight adolescents and underweight adolescents compared to normal weight. This dieting trend followed is a risk factor for developing eating disorders in the future. (22)

\section{Conclusion}

The body weight and size perception was distorted among adolescents of both sexes. The perceived body image perception when compared with their BMI was found to be incongruent across sexes. Girls have shown a higher body image discontent compared to boys in the present study. It was also observed that adolescents with higher BMls had followed diets or were following diets without clinical supervision and experienced mistreatment and discrimination among peers. The anthropometric measurements also suggested dual malnutrition (i.e. over nutrition as well as under nutrition) in both sexes. The factors influencing body image were self-perception and judgements by others, behaviors related with selffixation, social influences and inappropriate dietary practices and comparison with models and actors which explained for $58.75 \%$ of the variance.

\section{Recommendation}

The study emphasized the need to consider body image perception and dissatisfaction before planning any interventions to improve nutritional status among adolescents. This study calls for targeted interventions on developing realistic body image satisfaction and selfesteem using health-promoting behaviors.

\section{Limitation of the study}

Being a cross-sectional study, the interpretations related to the perceptions are based on the self-reported data of adolescents. Due to the limited sample size restricted to an urban area, the study outcomes may have limited generalizability.

\section{Relevance of the study}

The rising new perception on beauty and diet has contributed to unhealthy body image among adolescents which necessitates understanding of current pointers of body image satisfaction in relation to $\mathrm{BMI}$, to prevent faulty mismanagement of weight in adolescents. The study holds relevance with its multifactorial nature which captured perceptions and practices towards body image followed among adolescents.

\section{Authors Contribution}

$\mathrm{RH}$ contributed in designing the study, study protocol, data collection, data analysis and manuscript preparation. GMSR contributed to designing study, data analysis interpretation, manuscript preparation and also supervised the study.

\section{Acknowledgement}

[Understanding body image...] | Hedaoo RP et al

The current manuscript is an outcome of data collected under the ICMR-ICSSR funded research project titled "Development, validation and dissemination of comprehensive healthy eating and living index among adolescents". The authors acknowledge the support of Indian Council of Medical Research (ICMR) - Indian Council of Medical Research (ICSSR). The authors would like to thank the student volunteers, school management and school principals and teachers for their support and cooperation. The authors also thank The Director, ICMRNational Institute of Nutrition, Hyderabad for her encouragement. The authors would also like to thank Symbiosis Centre of Research and Innovation (SCRI), Symbiosis International (Deemed University), Pune for support and encouragement to conduct this study.

\section{References}

1. Kapur S. Adolescence: the stage of transition. Horizons of holistic education. 2015 Jul; 2:233-50.

2. Kostanski M, Fisher A, Gullone E. Current conceptualisation of body image dissatisfaction: have we got it wrong?. J Child Psychol Psychiatry. 2004 Oct;45(7):1317-25. doi: 10.1111/j.14697610.2004.00315.x. PubMed PMID: 15335351.[PubMed].

3. Rosewall JK, Gleaves DH, Latner JD. An examination of risk factors that moderate the body dissatisfaction-eating pathology relationship among New Zealand adolescent girls. J Eat Disord. 2018;6:38. doi: 10.1186/s40337-018-0225-z. eCollection 2018. PubMed PMID: 30473790; PubMed Central PMCID: PMC6240946.[PubMed].

4. Meadows A, Bombak AE. Yes, we can (no, you can't): Weight stigma, exercise self-efficacy, and active fat identity development. Fat Studies. 2019 May 4;8(2):135-53.

5. Schilder P, Wertman R. Imagem do corpo: as energias construtivas da psique. Martins Fontes; 1994.

6. Martin JB. The development of ideal body image perceptions in the United States. Nutrition Today. 2010 May 1;45(3):98-110.

7. Bašková $\mathrm{M}$, Holubčíková J, Baška T. Body-image Dissatisfaction and Weight-control Behaviour in Slovak Adolescents. Cent Eur J Public Health. 2017 Sep;25(3):216-221. doi: 10.21101/cejph.a4724. PubMed PMID: 29022681.[PubMed]

8. Golden NH, Schneider M, Wood C. Preventing Obesity and Eating Disorders in Adolescents. Pediatrics. 2016 Sep;138(3). doi: 10.1542/peds.2016-1649. Epub 2016 Aug 22. Review. PubMed PMID: 27550979.[PubMed]

9. Marengo D, Longobardi C, Fabris MA, Settanni M. Highly-visual social media and internalizing symptoms in adolescence: The mediating role of body image concerns. Computers in Human Behavior. 2018 May 1;82:63-9.

10. Thompson, J. K., Heinberg, L., and Tantleff, S. (1991). The physical appearance comparison scale. Behav. Ther. 14:174.

11. King'scollegeofLondonQuestionnaire https://www.kcl.ac.uk/ioppn/depts/psychology/research/Researc hGroupings/CADAT/Links/Body-Image-Questionnaire-(BIQ).pdf Accessed on 2 .5.2018.

12. http://sauce.pntic.mec.es/dtag0000/archivos_domi/body\%20ima ge.doc

13. Saleem, S.M. Modified Kuppuswamy scale updated for the year 2018. Paripex-Indian J Res, 2018;7;435.

14. Van den Broeck J, Willie D, Younger N. The World Health Organization child growth standards: expected implications for clinical and epidemiological research. Eur J Pediatr. 2009 Feb;168(2):247-51. doi: 10.1007/s00431-008-0796-9. Epub 2008 Aug 1. PubMed PMID: 18670787.[PubMed] 
INDIAN JOURNAL OF COMMUNITY HEALTH / VOL 32 / ISSUE NO 02 / APR - JUN 2020

15. Auerswald $M$, Moshagen $M$. How to determine the number of factors to retain in exploratory factor analysis: A comparison of extraction methods under realistic conditions. Psychol Methods. 2019 Aug;24(4):468-491. doi: 10.1037/met0000200. Epub 2019 Jan 21. PubMed PMID: 30667242.[PubMed].

16. Deshmukh VR, Kulkarni AA. Body Image and its Relation with Body Mass Index among Indian Adolescents. Indian Pediatr. 2017 Dec 15;54(12):1025-1028. doi: 10.1007/s13312-017-1205-0. Epub 2017 Aug 24. PubMed PMID: 28849771.[PubMed]

17. Giles DC, Maltby J. The role of media figures in adolescent development: Relations between autonomy, attachment, and interest in celebrities. Personality and individual differences. 2004 Mar 1;36(4):813-22.

18. Smith, Stacy L., Marc Choueiti and Katherine Pieper. "Gender Bias Without Borders. An Investigation of Female Characters in Popular Films Across 11 Countries." A report published by the Geena Davis Institute on Gender and Media.2014, Accessed 1.9.2018 2019. http://seejane.org/wp-content/uploads/gender-bias-withoutbordersexecutive-summary.pdf.
[Understanding body image...] | Hedaoo RP et a

19. Fardouly J, Pinkus RT, Vartanian LR. The impact of appearance comparisons made through social media, traditional media, and in person in women's everyday lives. Body Image. 2017 Mar;20:3139. doi: 10.1016/j.bodyim.2016.11.002. Epub 2016 Nov 28. PubMed PMID: 27907812.[PubMed].

20. MacCallum F, Widdows H. Altered Images: Understanding the Influence of Unrealistic Images and Beauty Aspirations. Health Care Anal. 2018 Sep;26(3):235-245. doi: 10.1007/s10728-016-0327-1. PubMed PMID: 27432005; PubMed Central PMCID: PMC6061013. [PubMed].

21. Ferguson CJ. The devil wears stata: Thin-ideal media's minimal contribution to our understanding of body dissatisfaction and eating disorders. Archives of Scientific Psychology. 2018 Aug 20;6(1):70.

22. Rohde P, Stice E, Marti CN. Development and predictive effects of eating disorder risk factors during adolescence: Implications for prevention efforts. Int J Eat Disord. 2015 Mar;48(2):187-98. doi: 10.1002/eat.22270. Epub 2014 Mar 6. PubMed PMID: 24599841; PubMed Central PMCID: PMC4156929.[PubMed].

\section{Tables}

\begin{tabular}{|c|c|}
\hline Variable & Group (\%) \\
\hline \multirow[t]{2}{*}{ Gender } & Boys $(n=74)(66)$ \\
\hline & Girls $(n=38)(34)$ \\
\hline \multirow[t]{4}{*}{ Religion } & Hindu (94.4) \\
\hline & Muslim (4.6) \\
\hline & Christian (0.5) \\
\hline & Sikh (0.5) \\
\hline \multirow[t]{2}{*}{ Family Type } & Joint (36.1) \\
\hline & Nuclear (63.9) \\
\hline Anthropometric Measures & Mean \pm SD \\
\hline Height (Cm) & $155.34 \pm 7.2$ \\
\hline Weight (Kg) & $44.50 \pm 1.05$ \\
\hline Body Mass Index (BMI) $\left(\mathrm{Kg} / \mathrm{m}^{2}\right)$ & $18.9 \pm 4.2$ \\
\hline BMI z-score & $-.51 \pm 1.8$ \\
\hline
\end{tabular}

TABLE 2 DESCRIPTIVE STATISTICS OF INDICATORS OF BODY IMAGE PERCEPTIONS EXPRESSED THROUGH ITEMS IN THE QUESTIONNAIRE ( $N=112)$

\begin{tabular}{|c|c|c|c|c|}
\hline \multirow[t]{3}{*}{ Variables } & \multirow[t]{3}{*}{ Responses } & Girls & Boys & Pooled \\
\hline & & $(n=38)$ & $(n=74)$ & $(n=112)(\%)$ \\
\hline & & (\%) & (\%) & \\
\hline \multirow[t]{3}{*}{ Body size and weight perception } & Too thin (underweight) & $0(0)$ & $2(2.7)$ & $02(1.7)$ \\
\hline & Too fat (overweight) & $16(42.1)$ & $16(21.6)$ & $32(28.5)$ \\
\hline & All right (normal weight) & $22(57.8)$ & $56(75.6)$ & $78(69.6)$ \\
\hline \multirow{2}{*}{$\begin{array}{l}\text { Satisfaction of adolescents with } \\
\text { their looks and body }\end{array}$} & Yes & $8(21.0)$ & $50(67.5)$ & $58(51.7)$ \\
\hline & No & 30 (78.9) & $24(37.8)$ & $54(48.3)$ \\
\hline \multirow{3}{*}{$\begin{array}{l}\text { Choice to change physical } \\
\text { appearance }\end{array}$} & Face & $9(23.6)$ & $23(31.0)$ & $32(28.5)$ \\
\hline & Body shape & 15 (39.4) & $18(24.3)$ & $33(29.4)$ \\
\hline & Nothing & $14(36.8)$ & $33(44.5)$ & $47(42.2)$ \\
\hline \multirow{3}{*}{$\begin{array}{l}\text { Importance given to opinion of } \\
\text { family, friends, others }\end{array}$} & A lot & $8(21.0)$ & $10(27.0)$ & $18(16.0)$ \\
\hline & A little & $18(47.3)$ & 37 (19.9) & $55(49.1)$ \\
\hline & Not at all & $12(31.5)$ & $27(10.3)$ & $39(34.8)$ \\
\hline \multirow{2}{*}{$\begin{array}{l}\text { Discrimination and mistreatment } \\
\text { observed due to physical } \\
\text { appearance }\end{array}$} & Yes & $1026.3)$ & $14(44.4)$ & $24(21.4)$ \\
\hline & No & $28(73.6)$ & $60(10.3)$ & $88(78.5)$ \\
\hline \multirow{2}{*}{$\begin{array}{l}\text { Followed dieting or following diet } \\
\text { presently }\end{array}$} & Yes & $7(18.4)$ & $14(44.4)$ & $21(18.7)$ \\
\hline & No & $31(81.5)$ & $60(10.3)$ & $91(81.3)$ \\
\hline
\end{tabular}


INDIAN JOURNAL OF COMMUNITY HEALTH / VOL 32 / ISSUE NO 02 / APR - JUN 2020

\begin{tabular}{|c|c|c|c|c|}
\hline \multirow{3}{*}{$\begin{array}{l}\text { Assets making the person } \\
\text { beautiful and attractive }\end{array}$} & Thinness & $10(26.3)$ & $10(10.3)$ & $20(17.8)$ \\
\hline & External beauty & $3(7.8)$ & $14(37.0)$ & $17(15.1)$ \\
\hline & Character & $25(6.5)$ & $50(4.4)$ & 75 (66.9) \\
\hline \multirow[t]{3}{*}{ Idols among adolescents } & Family members & $3(7.8)$ & $5(6.7)$ & $8(7.1)$ \\
\hline & Actors and Models & $35(92.1)$ & $60(81.0)$ & $95(84.8)$ \\
\hline & Sports persons & $0(0)$ & $9(12.1)$ & $9(8.0)$ \\
\hline \multirow{3}{*}{$\begin{array}{l}\text { Comparison with models and } \\
\text { actors }\end{array}$} & Good & $1(2.6)$ & $3(4.0)$ & $4(3.5)$ \\
\hline & Don't care & $24(63.1)$ & $62(83.7)$ & $86(76.7)$ \\
\hline & Frustrated and insufficient & $13(34.2)$ & 9 12.1) & 22(19.6) \\
\hline \multirow{3}{*}{$\begin{array}{l}\text { Physical appearance indicative of } \\
\text { happiness }\end{array}$} & A lot & $9(23.6)$ & $12(17.0)$ & 21(18.7) \\
\hline & Partially & $6(15.7)$ & $23(28.8)$ & $29(25.8)$ \\
\hline & Not at all & $23(60.5)$ & $39(5.9)$ & $62(55.3)$ \\
\hline \multirow{3}{*}{$\begin{array}{l}\text { Frequency of mirror usage to } \\
\text { check body shape and size }\end{array}$} & Most of the time & $24(63.1)$ & $8(28.1)$ & $32(28.5)$ \\
\hline & Accidently & $11(28.9)$ & $38(20.7)$ & $49(43.7)$ \\
\hline & Rarely & $3(7.8)$ & $28(7.4)$ & $31(27.6)$ \\
\hline \multirow{3}{*}{$\begin{array}{l}\text { Frequency of selfies to check } \\
\text { physical appearance }\end{array}$} & Often & $23(60.5)$ & $10(33.3)$ & $33(29.4)$ \\
\hline & Occasionally & $11(28.9)$ & 45 (14.1) & $56(50.0)$ \\
\hline & Rarely & $4(10.5)$ & $19(2.2)$ & $23(20.5)$ \\
\hline \multirow{3}{*}{$\begin{array}{l}\text { Usage of beauty apps to edit body } \\
\text { shape and size before putting it on } \\
\text { social media platforms }\end{array}$} & All the time & $21(55.2)$ & $3(28.1)$ & $24(21.4)$ \\
\hline & Sometimes & $13(34.2)$ & $38(24.4)$ & $51(45.5)$ \\
\hline & Never & $3(7.8)$ & $33(28.8)$ & $36(32.1)$ \\
\hline \multirow{3}{*}{$\begin{array}{l}\text { Comparison with people who } \\
\text { have a better figure or physique }\end{array}$} & Most of the time & $23(60.5)$ & $39(14.0)$ & $62(55.3)$ \\
\hline & Sometimes & $14(36.8)$ & $19(11.1)$ & $33(29.4)$ \\
\hline & Never & $1(2.6)$ & $15(20.2)$ & $16(14.2)$ \\
\hline
\end{tabular}

TABLE 3 SIGNIFICANT ASSOCIATIONS BETWEEN INDICATORS OF BODY IMAGE PERCEPTION, BMI AND GENDER

\begin{tabular}{|c|c|}
\hline \multicolumn{2}{|l|}{ Associations found between body image perception indicators and BMI } \\
\hline Items of the questionnaire & Chi-square ( $P$ value) \\
\hline Discrimination and mistreatment observed due to physical appearance & $8.37(\mathrm{P}<0.05)$ \\
\hline $\begin{array}{l}\text { Followed dieting or following diet presently without supervision from } \\
\text { Nutritionist/Dietician/Doctor }\end{array}$ & $7.48(P<0.05)$ \\
\hline \multicolumn{2}{|l|}{ Association between body image perception indicators and Gender } \\
\hline Indicators & Chi-square (P value) \\
\hline Choose to change physical appearance & $6.14(P<0.05)$ \\
\hline Idols among adolescents & $8.91(P<0.05)$ \\
\hline Comparison with models and actors & $7.75(P<0.05)$ \\
\hline Frequency of mirror usage to check body shape and size & $35.09\left(P<0.001^{*}\right)$ \\
\hline Frequency of selfies to check physical appearance & $26.07\left(\mathrm{P}<0.001^{*}\right)$ \\
\hline Usage of beauty apps to edit body shape and size before putting on social media platforms & $44.23\left(\mathrm{P}<0.001^{*}\right)$ \\
\hline Comparison with people who have a better perceived figure or physique & $6.77(P<0.05)$ \\
\hline
\end{tabular}

TABLE 4 IMPORTANT FACTORS THAT INFLUENCE BODY IMAGE PERCEPTION AND DISCONTENT OBTAINED THROUGH PRINCIPAL COMPONENT ANALYSIS

\begin{tabular}{|l|l|}
\hline Components & Variance (\%) \\
\hline Satisfaction of adolescents with their looks and body & 20.98 \\
\hline Body size and weight perception & \\
\hline Importance given to opinion of family, friends, others & \\
\hline Discrimination and mistreatment observed due to physical appearance & 18.77 \\
\hline Assets making the person beautiful and attractive & \\
\hline Component II- Behaviours related with self- fixation & \\
\hline
\end{tabular}


Frequency of mirror usage to check body shape and size

Frequency of selfies to check physical appearance

Usage of beauty apps to edit body shape and size before putting it on social media platforms

Comparison with people who have a better perceived figure or physique

Component III- Social influence related with body image

Choice to change physical appearance

Idols among adolescents

Physical appearance indicative of happiness

Component IV- Inappropriate dietary practice and undue comparison related with body image

Followed diet or following diet presently without supervision from a Nutritionist/Dietician/Doctor

Comparison with models and actors

\section{Figure}

FIGURE 1 BMI Z- SCORE CLASSIFICATION OF ADOLESCENTS ( $\mathrm{N}=112$ )

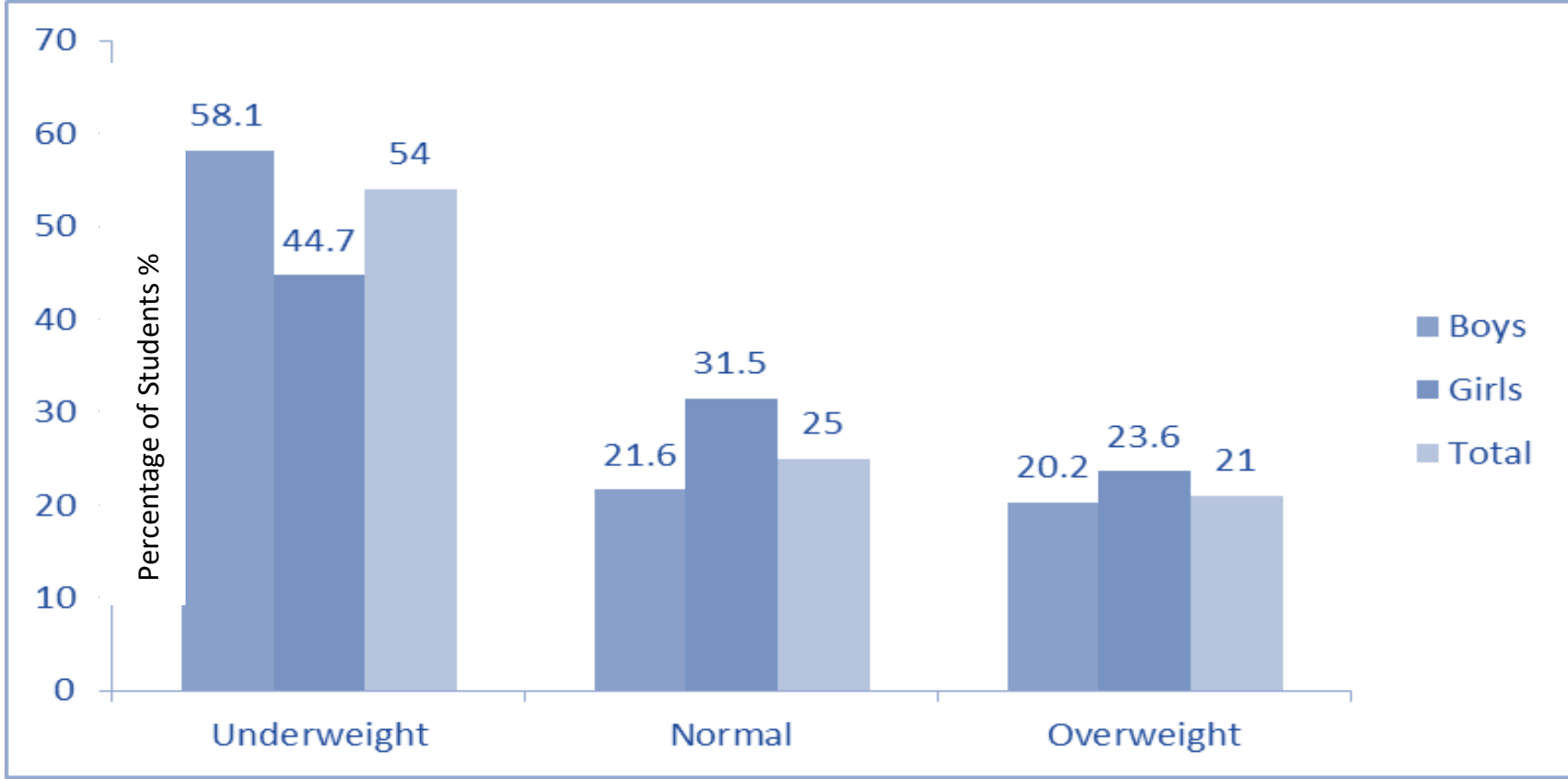

